\title{
Research on Problems and Countermeasures of Shaanxi Network Cars under the Shared Economy
}

\author{
Jiaojiao Mo \\ Xi'an Peihua University, Xi’an, Shaanxi, 710125
}

Keywords: Shaanxi network cars; shared economy; problems and countermeasures

\begin{abstract}
As an emerging economic format, the operation mode of network cars is quite different from that of the traditional taxi industry, and the Internet characteristics it presents bring greater difficulty to the government regulation. From the perspective of regulatory principles, government regulation should be good at using self-regulation of individuals and industries, and to a certain extent, moderate regulation to form a benign interaction between government regulation and self-regulation. From the perspective of the selection of regulatory methods, the government should re-integrate the traditional cost-benefit analysis, administrative licensing and other regulatory methods, and at the same time play the soft law on the production of the shared economic model, and then through the specific regulatory measures to achieve the standardization and legal operation of network cars.
\end{abstract}

\section{Introduction}

Along with the rise of the sharing economy, some emerging economic formats have been developed, such as online car, shared bicycle, and shared car. These new formats not only bring great convenience to social life, but also have problems such as how to effectively regulate them. Some scholars have fully affirmed the benefits of the innovation of the sharing economy for the society, and analyzed the interaction between innovation and regulation. They believe that government regulation must first grasp the starting point of regulation, whether it is regulated and when it is very strict for enterprises. important. Government regulation must not only be good at using self-regulation, but also adopt experimental methods to continuously improve regulatory measures. It is necessary to pay attention to the innovation of regulatory concepts, the interaction between regulation and governance, and the relationship between government, market and society and its process [1]. Some scholars have put forward a series of opinions from the perspective of self-regulation, and believe that it is necessary to give play to the self-regulation advantage of economic entities such as enterprises, and form a regulatory model that complements and supports each other in government regulation and self-regulation [2]. Some scholars start from the regulatory structure, try to propose a hierarchical-classification regulation structure, and adopt different regulatory measures for network service providers, carriers, vehicles and drivers [3]. These studies elaborated on the regulation of the sharing economy from different angles, but the research on the difficulties and solutions to the actual implementation of the network car is insufficient. Based on this, this paper attempts to analyze the regulatory predicament currently faced by the network car, summarize its regulatory principles, and then sort out the regulatory tools for the network car, select the appropriate regulatory methods, and propose a specific network car routing path.

\section{The Regulatory Dilemma of Network Car in the Context of Shared Economy}

In recent years, the sharing economy based on Internet technology has developed rapidly. The sharing economy uses the Internet to quickly and efficiently collect information, which breeds a new economic model. Under this economic model, consumers can also become operators, use their idle resources, and reach a paid sharing agreement with the people in need to stimulate new markets and demand. Net car is an important performance. One of the forms has been widely recognized by people once it appears. However, the so-called sharing economy is also prone to some negative 
effects, such as information leakage, security risks and its own legality. These problems are difficult to solve through the regulatory methods adopted by the government. The regulatory difficulties of the network car are mainly reflected. In the following aspects. First, the traditional regulatory concept does not conform to the characteristics of shared economic development. The sharing economy is different from the traditional economic model and is characterized by openness, inclusiveness, blending and variability. The government's regulation of the traditional economy is still relatively strict, and the government has a large level of market supervision and a wide range of issues. The above-mentioned regulatory thinking is obviously not applicable to the new economy of the sharing economy, and may be a hindrance. Therefore, it is difficult to achieve the desired effect by managing the network car with the regulatory thinking of the traditional taxi industry.

Second, traditional pre-regulatory means do not fit in with the nature of the shared economy. The traditional taxi market supervision relies more on ex ante means, such as setting industry access permits and issuing business licenses to regulate its industry development. At present, the State has formulated the "Interim Measures for the Administration of Network Appointment of Taxi Management" and the "Guiding Opinions on Deepening Reform to Further Promote the Healthy Development of the Taxi Industry (Consultation Draft)”. Network management method.

Third, traditional single regulators cannot meet the needs of the sharing economy. As a product of the Internet, the network car is highly efficient and fast-changing, and traditional regulation methods cannot timely supervise it. The operating mechanism of the network car is mainly registered by the private car owners and travellers on the network platform, through the release of travel information, and then by the owner of the car. This kind of operation mode will inevitably lead to problems such as leakage of personal information, plus the characteristics of rapid information dissemination and wide coverage, and the traditional single regulatory body cannot do anything about it. As the main body of regulation, the government has a single regulatory body and low regulation efficiency. The problems of long-term law enforcement, selective law enforcement, and evasion of law enforcement are more prominent, and the regulatory effect is limited. Therefore, how the government integrates the functions of different regulatory agencies and seeks cooperation with other entities in combination with the characteristics of the Internet to achieve positive interaction between supervision and Internet development is an urgent concern.

Fourth, the lag of legislation is difficult to meet the changing needs of the Internet economy. Under the traditional supervision mode, the government provides legislative force to provide enforcement force for regulation to ensure the smooth progress of regulation. As a product of the Internet background, the network is about to develop rapidly, which is in stark contrast to the lag of legislation and its procedural requirements. There are many legislative start-up procedures, and the legislative cycle is long. It is afraid that the regulation of the network-only car through legislation will cause such a situation: Net-cars have already derived other forms, and after more new problems, the relevant laws and regulations are official. Introduced. The government is accustomed to using hard law as a means of regulation. However, the rapid development of the network car and the variety of modes make the traditional hard law system difficult to produce good results. Although the hard law has its advantages, but for the fast-changing Internet sharing economy, the soft law may be more effective in timely and effective production [4].

\section{The Regulation Principle of Network Car in the Context of Shared Economy}

In fact, the sharing economy has implemented the development concept of innovation, coordination, green and sharing. In this context, the shared subject may be every member of the society. If the past government is also used as a single subject for supervision, it is difficult to meet the needs of the sharing economy. Therefore, government supervision should shift to a unified supervision model of the whole people, from a single regulatory body to a multi-subject co-governance [5]. The government should gradually simplify its administration and decentralize its power, and decentralize part of its supervision power to other social entities, and cooperate with enterprises and the public to achieve a win-win goal of supervision. What the government needs to do is to clarify the division of responsibilities and responsibilities of each subject, and to develop 
corresponding procedures to ensure the legal implementation of regulatory measures. On the one hand, as the main body of supervision, if the government monopolizes its supervisory responsibilities, it will lead to excessive government supervision costs. On the other hand, the government cannot flexibly grasp the development trend of the sharing economy and is likely to curb its healthy development. Therefore, the idea of government regulation needs to be changed.

The development concept of "Internet + " is to connect the government, society and various enterprises through the Internet, and work together in a more open and inclusive manner to achieve a win-win goal through cooperation. The regulatory path of the network car must also adhere to such a "shared" cooperation philosophy, abandoning the traditional thinking of the government as the sole supervisory body, so that all relevant subjects can participate in the supervision of the network car. In this way, it will not only help improve the government's regulatory efficiency, but also reduce the government's regulatory costs and maximize the regulatory objectives.

To achieve the common supervision of the network car, we must first fully respect the self-regulation of the network car platform. Article 13 of the Administrative Licensing Law stipulates that: In the case that the market mechanism can self-regulate and the industry organization can solve the problem on its own, the government should not set licensing matters, and the supervision of the network car should be more so. The government should give full play to the function of market allocation of resources and not easily interfere with the autonomous operation of the network car platform.

First of all, the network car platform is more professional, able to fully understand the technical knowledge in the industry, and grasp the operation and development trend of the network car more accurately [2]. Self-regulation by it can fully exploit its advantages and solve problems in the industry in a timely and appropriate manner. Secondly, the network car platform has more information, can make more accurate predictions on the market, give full play to the role of market allocation resources, and is conducive to the development of the sharing economy. Once again, the network car as the main body of regulation can reduce the government's code-based costs and achieve greater benefits at the lowest cost. Finally, the self-regulation of the network car is more efficient. As a subject of regulation and regulation, the network car can better understand the problems that may exist in its operation, and solve the problem more flexibly and quickly by formulating regulations or industry rules.

The network car is an economic model in which private car owners and passengers register on the network platform and the supply and demand information is released by the platform. The traffic congestion, the unstable supply and the safety of the ride that may be caused by the network car can be solved through the supervision of the platform itself. For example, an online car service evaluation system, a real-name certified private car owner identity, and regular inspections of vehicle safety conditions can be established. In the context of "Internet +", the government should fully trust the responsibility and regulatory capacity of the self-regulation of the network platform, and realize the full development of the sharing economy through self-regulation of the market and self-regulation of the network platform. Under the market economy, the government should give full play to the self-regulating role of the market. Only in the event of market failure, the government must play the regulatory role of "tangible hands". However, respecting the self-regulating role of the market does not mean that the government withdraws from the stage of regulation, but combines self-regulation with government regulation. As the main body of self-regulation, the network platform will inevitably have problems that only pay attention to its own industry interests and low attention to other related subjects, and it is easy to cause excessive pursuit of its own interests without regard to the disadvantages of other stakeholders. Therefore, in the event that some problems that are difficult to solve on the network platform occur, the government still needs to exert its coercive force and use mandatory regulatory measures and penalties to ensure the stable development of the sharing economy.

\section{Conclusion}

Internet big data has not only changed the economic model and our way of life, but also has a 
profound impact on the future development of society. As a modern economic tool developed under the "Internet +" mode, the wide-ranging application of the network car has brought about tremendous changes in social life. For similar emerging economic formats, the government cannot simply adopt a conservative attitude to suppress its development for market security. Instead, it should conform to the trend of social development, gradually change the traditional regulatory thinking, and abandon the regulatory model that relies excessively on ex ante regulation and single-subject regulation. The combination of government regulation and self-regulation, and the combination of soft law and hard law to regulate the development of the sharing economy. In short, for the new economic format, the government should respond positively and take the initiative to implement innovations in regulatory concepts and regulatory measures by formulating reasonable regulatory measures.

\section{Acknowledgements}

Fund Project: Special Research Project of Shaanxi Provincial Department of Education in 2018: Research on the Supervision Mode of Shaanxi Net Cars in the Background of Sharing Economy

\section{References}

[1] Gao Qinwei. Sharing economic innovation and government regulation response [J]. Jurist, 2017 (4).

[2] $\mathrm{Li}$ Honglei. On the regulation system of the Internet--between government regulation and self-regulation [J]. Global Law Review, 2014 (1).

[3] Chen Yuefeng. The "Internet +" regulatory structure - as an example of "network car" regulation [J]. Jurist, 2017 (1).

[4] Luo Haocai, Zhou Qiang. Soft law governance in the construction of legal government [J]. Jianghai Academic Journal, 2016 (2).

[5] Zhao Wei. The orientation and task of "government rule of law" under the concept of building and sharing the whole nation [J]. Journal of Fujian Administration College, 2017(2). 